\title{
SISTEM PENGENDALI KONVEYOR BELT PADA PT. XYZ TANGERANG
}

\author{
Sumardi Sadi \\ Universitas Muhammadiyah Tangerang \\ E-mail: mardiesadi99@gmail.com
}

\begin{abstract}
ABSTRAK
Sistem kendali conveyor belt pada PT. XYZ merupakan alat untuk memindahkan suatu produk yang dihasilkan dari bagian produksi ke gudang penyimpanan. Sistem konveyor banyak digunakan diberbagai macam industri, baik industry kecil maupun besar, yang tentetunya konveyor tersebut sebagai pengangkut dan pemindah barang pada suatu proses produksi. Dalam penelitian ini metode yang di gunakan adalah dengan cara mengamati dan mempelajari sistem kontrol dari conveyor belt tersebut beserta alatnya berupa motor, gearbox dan inverter yang diatur di dalam panel box untuk membawa box produk yang berisi produk dari suatu proses produksi. Dari penelitian ini diperoleh kesimpulan dalam 1 hari conveyor belt tersebut dapat membawa kurang lebih 600 Dus (tempat produk) pada speed inverter 28-32 Rpm yang berisi hasil produksi dari bagian produksi ke gudang, dibandingkan dengan membawa manual yang membutuhkan waktu yang lama dan tenaga yang kuat. Dengan adanya konveyor, membuat perusahaan menjadi efektif dan efisien dalam membawa dan menata hasil produksi.
\end{abstract}

Kata Kunci: Conveyor, Sistem Kontrol, Motor, Gear Box, Panel Box.

\section{PENDAHULUAN}

\subsection{LATAR BELAKANG MASALAH}

Seiring dengan perkembangan zaman maka kemajuan teknologi juga berkembang dengan pesat sehingga persaingan didalam dunia industri sendiri menuntut agar adanya peningkatan ketersediaan peralatan guna mendukung proses produksi suatu perusahaan. Dengan meningkatnya kebutuhan akan penggunaan teknologi guna meningkatkan produktivitas maka kebutuhan perawatan semakin besar juga.

Ada banyak faktor yang dapat mempengaruhi produksi salah satunya dengan sistem produksi yang handal, dalam hal ini adalah mesin serta komponen lainnya dapat beroperasi tanpa mengalami kerusakan pada saat proses produksi berlangsung. Secara alamiah tidak ada barang yang dibuat oleh manusia yang tidak dapat rusak akan tetapi usia pemakaian dapat diperpanjang dengan melakukan perbaikan berkala dengan suatu aktivitas yang dikenal sebagai pemeliharaan (maintenance).

Oleh karena itu teknologi otomasi industri sangat pesat dengan semakin banyak industri yang menggunakan sistem otomasi dalam menjalankan proses-proses produksinya. Sistem otomasi pada conveyor belt tersebut masih penggunaan sistem kendali konvensional yang terdiri dari beberapa komponen yaitu relai, kontaktor, dan kontraktor magnetik, hanya menambahkan alat yang bernama inverter di dalamya penggunaan kontrolnya. 


\subsection{IDENTIFIKASI MASALAH}

Berdasarkan latar belakang diatas, penggunaan sistem kontrol conveyor belt pada dunia industri sangat berpengaruh besar. Sehingga dapat di rumuskan permasalahan yang akan dibahas dalam penelitian ini yaitu bagaimana sistem otomasi kontrol conveyor belt di dunia industri agar dapat menghasilkan kerja conveyor belt yang maksimal.

\subsection{BATASAN MASALAH}

Agar permasalahan yang akan dibahas tidak semakin melebar serta berjalan dengan baik sesuai dengan alurnya maka dalam penelitian ini diperlukan adanya batasan-batasan masalah. Batasan-batasan masalah yang digunakan anatara lain: Memaparkan sistem otomasi kontrol pada conveyor belt.

\subsection{TUJUAN DAN MANFAAT PENULISAN}

Tujuan dari Penelitian ini adalah untuk Mendapatkan pengetahuan tentang ilmu di lingkungan kerja yang sebenarnya, mengetahui sistem kontrol otomasi conveyor belt dengan inverter dan mengetahui dan mempelajari cara pemasangan conveyor belt dengan inverter.

\subsection{METODE PENELITIAN}

Dalam penelitian ini, menggunakan beberapa metode, antara lain:

1. Metode observasi pengamatan, adalah metode pengumpulan data dengan melakukan pengamatan-pengamatan secara langsung terhadap obyek yang akan dilaporkan dan mencatat segala yang berhubungan dengan pembuatan laporan.

2. Metode wawancara, adalah metode pengumpulan data dengan melakukan tanya jawab secara langsung, guna memperoleh informasi dan data yang dibutuhkan .

Metode study literatur, adalah metode pengumpulan data dengan cara membaca dan mempelajari buku-buku referensi maupun pencarian di situs-situs internet yang berhubungan dengan pembuatan laporan.

\section{LANDASAN TEORI}

\subsection{MOTOR LISTRIK 3 FASA}

Motor induksi tiga fasa merupakan motor elektrik yang paling banyak digunakan dalam dunia industri. Salah satu kelemahan motor induksi yaitu memiliki beberapa karakteristik parameter yang tidak linier, terutama resistansi rotor yang memiliki nilai yang bervariasi untuk kondisi operasi yang berbeda, sehingga tidak dapat mempertahankan kecepatannya secara konstan bila terjadi perubahan beban. Oleh karena itu untuk mendapatkan kecepatan yang konstan dan peformansi sistem yang lebih baik terhadap perubahan beban dibutuhkan suatu pengontrol.

Motor induksi 3 fasa adalah alat penggerak yang paling banyak digunakan dalam dunia industri. Hal ini dikarenakan motor induksi mempunyai konstruksi yang sederhana, kokoh, harganya relatif murah, serta perawatannya yang mudah, sehingga motor induksi mulai menggeser penggunaan motor DC pada industri. Motor induksi memiliki beberapa parameter yang bersifat non-linier, terutama resistansi rotor, yang memiliki nilai bervariasi untuk kondisi operasi yang berbeda. Hal ini yang menyebabkan pengaturan pada motor induksi lebih rumit dibandingkan dengan motor DC. Salah satu kelemahan dari motor induksi adalah tidak mampu mempertahankan kecepatannya dengan konstan bila terjadi perubahan beban. Apabila terjadi perubahan beban maka kecepatan motor induksi akan menurun. Untuk mendapatkan kecepatan konstan serta memperbaiki kinerja motor induksi terhadap perubahan beban, maka dibutuhkan suatu pengontrol.

Penggunaan motor induksi tiga fasa di beberapa industri membutuhkan performansi yang tinggi dari motor induksi untuk dapat 
mempertahankan kecepatannya walaupun terjadi perubahan beban. Salah satu contoh aplikasi motor induksi yaitu pada industri kertas. Pada industri kertas ini untuk menghasilkan produk dengan kualitas yang baik, dimana ketebalan kertas yang dihasilkan dapat merata membutuhkan ketelitian dan kecepatan yang konstan dari motor penggeraknya, sedangkan pada motor induksi yang digunakan dapat terjadi perubahan beban yang besar.

Beberapa penelitian pengaturan kecepatan motor induksi yang telah dilakukan antara lain oleh Brian Heber, Longya Xu dan Yifan Tang (1997) menggunakan kontroller logika fuzzy untuk memperbaiki performansi kontroller PID pada pengaturan kecepatan motor induksi. Demikian juga penelitian yang dilakukan oleh Mohammed dkk. (2000) mengembangkan kontroller fuzzy yang digunakan untuk menala parameter PI. Kontroller fuzzy juga dikembangkan pada penelitian yang dilakukan Chekkouri MR dkk. (2002) dan Lakhdar M \& Katia K (2004) dengan melengkapi mekanisme adaptasi pada kontroller fuzzy pada pengaturan motor induksi. Pada penelitian ini dirancang suatu pengaturan kecepatan motor induksi 3 fasa dengan menggunakan pengontrol adaptif fuzzy. Dengan adanya pengaturan kecepatan ini diharapkan kecepatan motor induksi dapat konstan sesuai yang diinginkan, walaupun mendapat perubahan beban, sehingga menghasilkan performansi motor induksi yang tinggi.

Motor induksi merupakan motor arus bolak balik (ac) yang paling luas penggunaannya. Penamaannya berasal dari kenyataan bahwa arus rotor motor ini bukan diperoleh dari sumber tertentu, tetapi merupakan arus yang terinduksi sebagai akibat adanya perbedaan relative antara putaran rotor dengan medan putar (rotating magnetic field) yang dihasilkan oleh arus stator.

Belitan stator yang dihubungkan dengan suatu sumber tegangan tiga fasa akan meng- hasilkan medan magnet yang berputar dengan kecepatan sinkron ( $n s=120 \mathrm{f} / 2 \mathrm{p}$ ). Medan putar pada stator tersebut akan memotong konduktor-konduktor pada rotor, sehingga terinduksi arus dan sesuai dengan Hukum Lentz, rotor pun akan ikut berputar mengikuti medan putar stator. Perbedaan putaran relative antara stator dan rotor disebut slip. Bertambahnya beban, akan memperbesar kopel motor, yang oleh karenanya akan memperbesar pula arus induksi pada rotor, sehingga slip antara medan putar stator dan putaran rotor pun akan bertambah besar. Jadi, bila beban motor bertambah, putaran rotor cenderung menurun. Dikenal dua tipe motor induksi yaitu motor induksi dengan rotor belitan dan rotor sangkar.

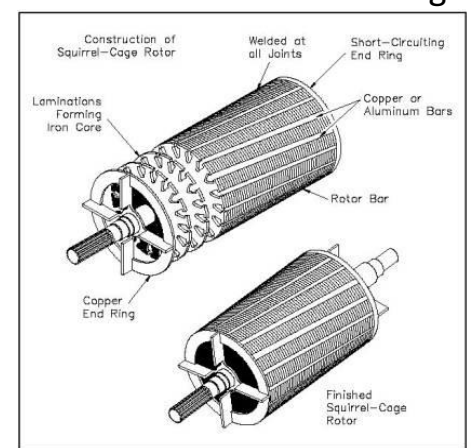

Gambar 2.1 Rotor Belitan

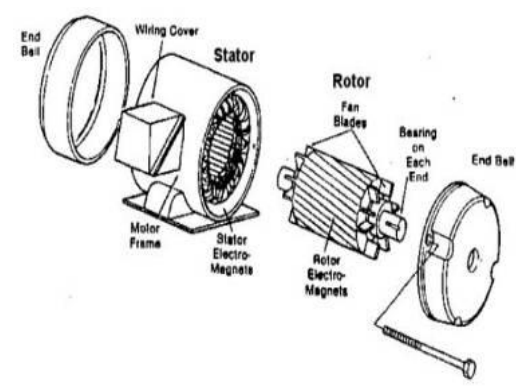

Gambar 2.2 Rotor Sangkar

Sebelum kita membahas bagaimana rotating magnetic field (medan putar) menyebabkan sebuah motor berputar, marilah kita tinjau bagaimana medan putar ini dihasilkan. Gambar berikut menunjukkan sebuah stator tiga fasa dengan suplai arus bolak balik tiga fasa pula. Belitan stator terhubung $\mathrm{Y}$ (wye). Dua belitan pada masing- 
masing fasa dililitkan dalam arah yang sama. Sepanjang waktu, medan magnet yang dihasilkan oleh setiap fasa akan tergantung kepada arus yang mengalir melalui fasa tersebut. Jika arus listrik yang melalui fasa tersebut adalah nol (zero), maka medan magnet yang dihasilkan akan nol pula. Jika arus mengalir dengan harga maksimum, maka medan magnet berada pada harga maksimum pula. Karena arus yang mengalir pada sistem tiga fasa mempunyai perbedaan $120^{\circ}$, maka medan magnet yang dihasilkan juga akan mempunyai perbedaan sudut sebesar $120^{\circ}$ pula. Ketiga medan magnet yang dihasilkan akan membentuk satu medan, yang akan beraksi terhadap rotor. Untuk motor induksi, sebuah medan magnet diinduksikan kepada rotor sesuai dengan po-laritas medan magnet pada stator. Karenanya, begitu medan magnet stator berputar, maka rotor juga berputar agar bersesuaian dengan medan magnet stator.

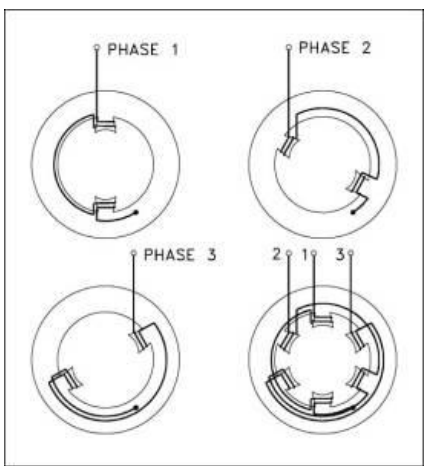

Gambar 2.3 Medan magnet stator 3 fasa

Pada sepanjang waktu, medan magnet dari masing-masing fasa bergabung untuk menghasilkan medan magnet yang posisinya bergeser hingga beberapa derajat. Pada akhir satu siklus arus bolak balik, medan magnet tersebut telah bergeser hingga $360^{\circ}$, atau satu putaran. Dan karena rotor juga mempunyai medan magnet berlawanan arah yang diinduksikan kepadanya, rotor juga akan berputar hingga satu putaran.

\subsection{Gear Box}

Gear box merupakan komponen meka- nikal yang menstranmisikan daya dan gerakan diantara sumbunya. Gear box juga dapat mengubah arah putaran dan mengubah gerakan rotasi menjadi gerakan linier. Fungsi gear box untuk merenduksi kecepatan pada conveyor sehingga putaran conveyor tetap stabil dan tidak terlalu cepat.

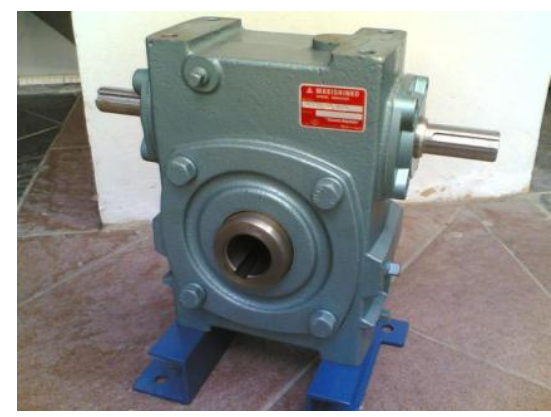

Gambar 2.4 Gear box

Prinsip Kerja Gearbox;

Putaran dari motor diteruskan ke input shaft (poros input) melalui hubungan antara clutch kopling, kemudian putaran diteruskan ke main shaft (poros utama), torsi momen yang ada di mainshaft diteruskan ke spindel mesin, karena adanya perbedaan rasio dan bentuk dari gigi-gigi tersebut sehingga rpm atau putaran spindel yang di keluarkan berbeda, tergantung dari rpm yang di inginkan. Berikut penjelasan beberapa part yang terdapat dalam gearbox:

\section{Input Shaft (Poros Input)}

Input shaft adalah komponen yang menerima momen output dari unit kopling, poros input juga befungsi untuk meneruskan putaran dari clutch kopling ke mainshaft (poros utama), sehingga putaran bisa di teruskan ke gear-gear. Input shaft juga sebagai poros dudukan bearing dan piston ring, selain itu berfungsi juga sebagai saluran oli untuk melumasi bagian dari pada input shaft tersebut.

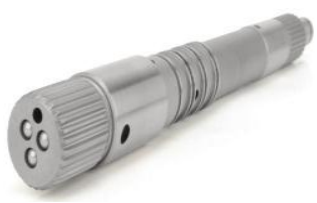

Gambar 2.5 Input Shaft (Poros Input) 


\section{Gear Shift Housing (Rumah Lever Pe- mindah Rpm)}

Gear shift housing adalah housing dari pada lever pemindah gigi yang berfungsi untuk mengatur ketepatan perpindahan gigi, apabila gigi sudah dipindahkan maka lever akan terkunci sehingga lever tidak bisa berpindah sendiri pada saat spindel sedang berputar.

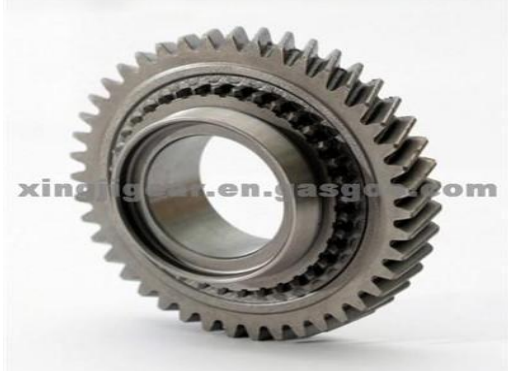

Gambar 2.6 Gear Shift Housing (Rumah Lever Pemindah RPM)

\section{Main Shaft (Poros Utama)}

Main shaft yang berfungsi sebagai tempat dudukan gear, sinchromest, bearing dan komponen-komponen lainnya. Main shaft juga berfungsi sebagai poros penerus putaran dari input shaft sehingga putaran dapat di teruskan ke spindel, main shaft juga berfungsi sebagai saluran tempat jalannya oli.

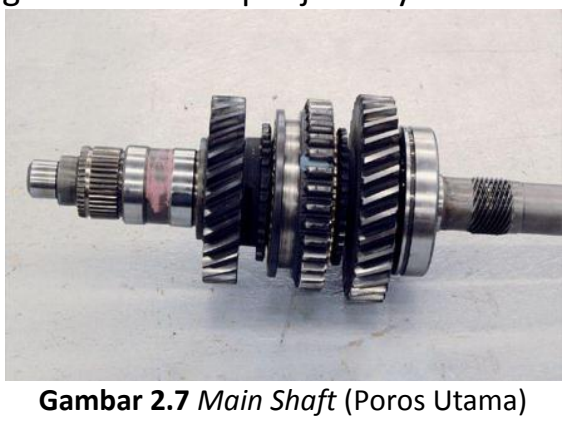

\section{Planetary Gear Section (Unit Gigi Plane- tari)}

Planetary adalah alat pengubah rpm di suatu range tertentu dimana rpm dapat di ubah sesuai dengan kebutuhan proses pengerjaan dan dapat pula mengubah arah putaran spindel.

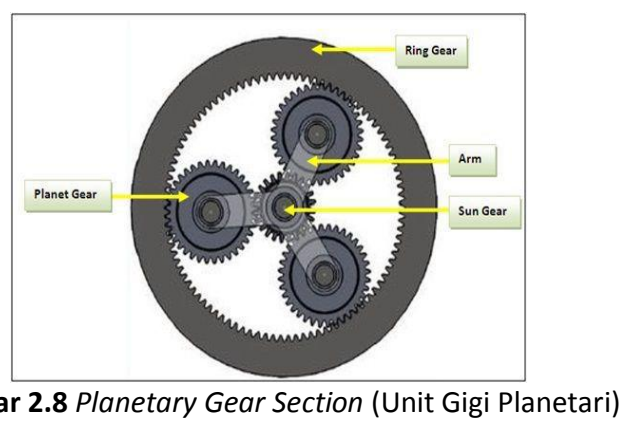

\section{Oil Pump Assy (Pompa Oli)}

Oil pump berfungsi untuk memompa dan memindahkan oli dari transmisi case (rumah transmisi) menuju ke sistem untuk dilakukan pe-lumasan terhadap komponen-komponen yang ada di dalam transmisi secara menyeluruh.

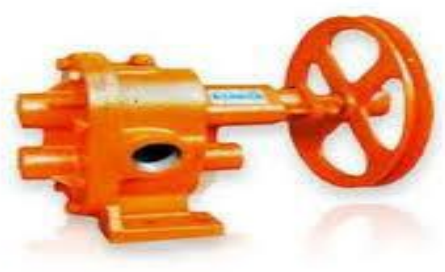

Gambar 2.9 Oil Pump Assy (Pompa Oli)

\section{Clucth Housing}

Clutch housing adalah rumah dari clucth kopling yang berfungsi sebagai pelindung clutch kopling, clutch housing juga berfungsi sebagai tempat dudukan dari pada oil pump dan input shaft.

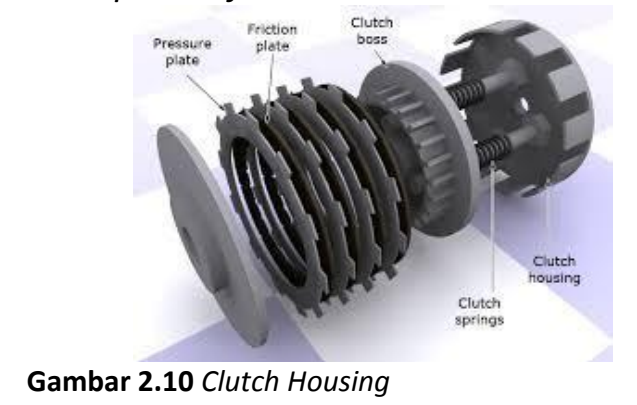

\section{Transmisi Gear (Roda Gigi Transmisi)}

Transmisi gear atau roda gigi transmisi berfungsi untuk mengubah input dari motor menjadi output gaya torsi yang meninggalkan transmisi sesuai dengan kebutuhan mesin. 


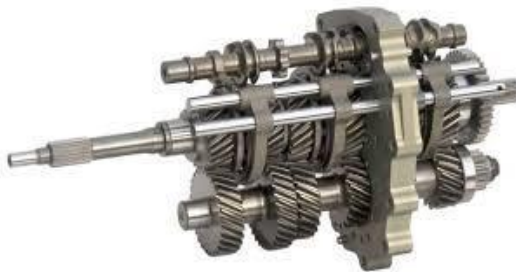

Gambar 2.11 Transmisi Gear (Roda Gigi Transmisi)

\section{Bearing}

Bearing berfungsi untuk menjaga kerenggangan dari pada shaft (poros), agar pada saat unit mulai bekerja komponen yang ada di dalam transmisi tidak terjadi kejutan, sehingga transmisi bisa bekerja dengan smooth (halus).

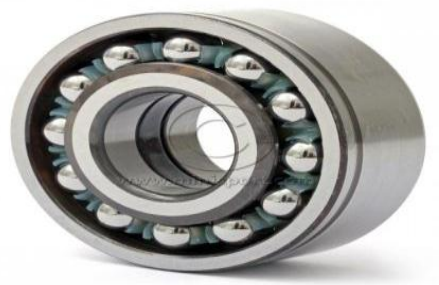

Gambar 2.11 Bearing

\section{Piston Ring (Ring Penyekat Oli)}

Piston ring berfungsi sebagai penyekat agar tidak terjadi kebocoran pada sistem pelumasan, piston ring juga berfungsi sebagai pengencang input shaft agar input shaft tidak renggang pada saat unit berjalan.

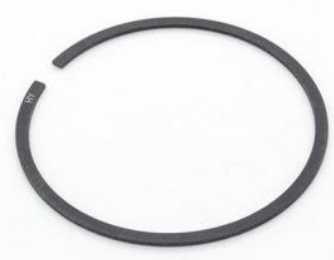

Gambar 2.12 Piston Ring (Ring Penyekat Oli)

\section{Sun Gear (Gigi Matahari)}

Sun gear berfungsi untuk meneruskan putaran ke planetary gear section. Sun gear berhubungan langsung dengan gear yang ada pada unit planetary yang berfungsi sebagai penerus putaran, momen dari transmisi.

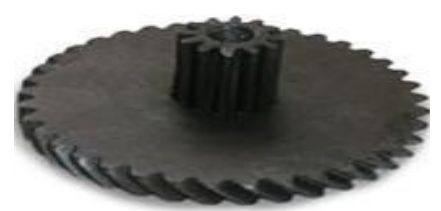

Gambar 2.13 Sun Gear (Gigi Matahari)

\section{Oil Filter (Filter Oli)}

Oil filter adalah komponen yang berfungsi untuk menyaring oli dari kotoran. Oli harus di saring, agar komponen transmisi tidak cepat aus yang disebabkan karena terjadinya gesekan antara komponen yang dapat menimbulkan geram-geram. Sehingga oli yang masuk ke sistem harus disaring dulu agar unit transmisi tetap baik.

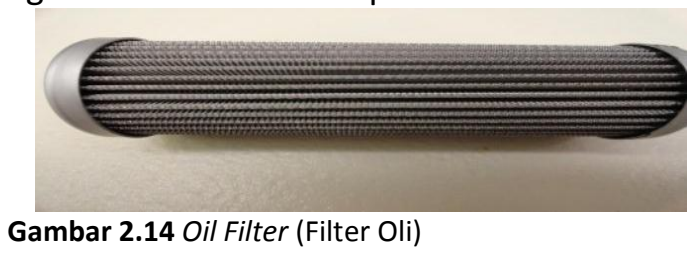

\section{Oil pipa (Pipa Oli)}

Oil pipa adalah pipa oli tipe batang, yang berfungsi sebagai saluran oli untuk menyalurkan oli dari transmisi case ke planetary gear section untuk dilakukan pelumasan terhadap unit planetary.

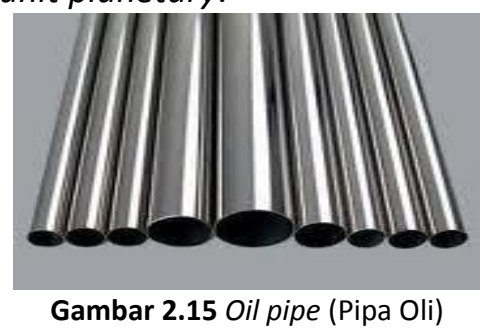

\subsection{Sensor Photodioda}

Photodioda merupakan sensor cahaya semikonduktor yang dapat mengubah besaran cahaya menjadi besaran listrik. Photodioda bekerja berdasarkan intensitas cahaya. Jika photodioda terkena cahaya maka photodioda bekerja seperti dioda pada umumnya tetapi jika tidak mendapat cahaya maka photodioda akan berperan seperti resistor dengan nilai tahanan yang besar sehingga arus listrik tidak dapat mengalir. 

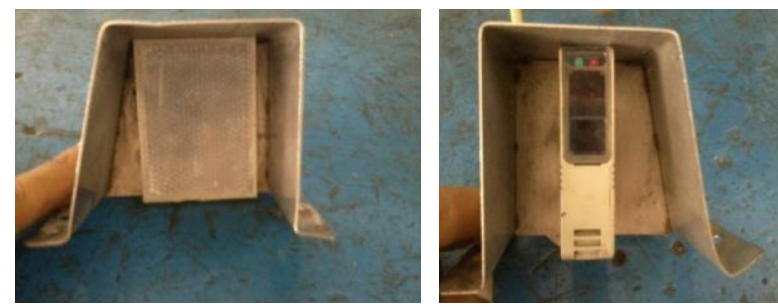

Gambar 2.16 Sensor Photodioda

\subsection{SISTEM KONTROL YANG BERADA DI DALAM PANEL BOX}

Dalam berjalannya sebuah conveyor selain di butuhkan motor dan gear box, conveyor juga di gerakkan oleh sistem kontrol yang berada di panel box. Di dalam panel tersebut banyak peralatan listrik yang berpengaruh besar dalam bekerjanya conveyor, antara lain:

\section{MCCB (Moulded Case Circuit Breaker)}

MCCB adalah Circuit Breaker pembatas arus apabila terdapat arus beban yg melebihi batas-batasnya. MCCB ini dipakai hampir sama dgn MCB tetapi dgn batas arus beban yg lebih besar dari 100 Ampere sampai dgn 1600 Ampere.

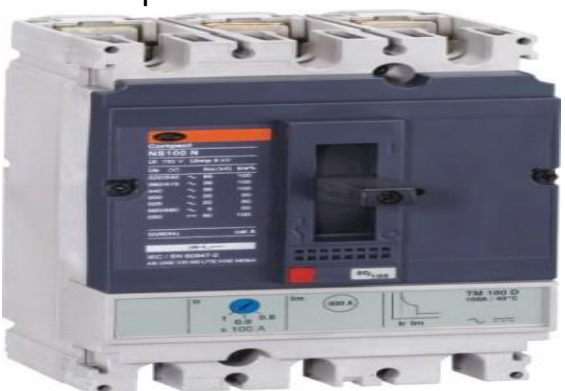

Gambar 2.17 MCCB (Moulded Case Circuit Breaker)

Dalam memilih circuit breaker hal-hal yang harus dipertimbangkan adalah:

- Karakteristik dari sistem dimana circuit breaker tersebut dipasang.

- Kebutuhan akan kontinuitas pelayanan sumber daya listrik.

- Aturan-aturan dan standar proteksi yang berlaku.
Karakteristik sistem:

1. Sistem tegangan

Tegangan operasional dari circuit breaker harus lebih besar atau minimum sama dengan tegangan sistem.

2. Frekuensi sistem

Frekuensi pengenal dari circuit breaker harus sesuai dengan frekuensi sistem. Circuit breaker Merlin Gerin dapat beroperasi pada frekuensi 50 atau 60 $\mathrm{Hz}$.

3. Arus pengenal

Arus pengenal dari circuit breaker harus disesuaikan dengan besarnya arus beban yang dilewatkan oleh kabel, dan harus lebih kecil dari arus ambang yang diijinkan lewat pada kabel.

4. Kapasitas pemutusan

Kapasitas pemutusan dari circuit breaker harus paling sedikit sama dengan arus hubung singkat prospektif yang mungkin akan terjadi pada suatu titik instalasi dimana circuit breaker tersebut dipasang.

5. Jumlah pole dari circuit breaker .

6. Jumlah pole dari circuit breaker sangat tergantung kepada sistem pembumian dari sistem.

Kebutuhan kontinuitas sumber daya tergantung dari kebutuhan tingkat kontinuitas pelayanan sumber daya listrik, dalam memilih circuit breaker harus diperhatikan:

1. Diskriminasi total dari dua circuit breaker yang ditempatkan secara seri.

2. Diskriminasi terbatas (sebagian), diskriminasi hanya dijamin sampai tingkat arus gangguan tertentu.

\section{Kontaktor (Magnetik Contactor)}

Kontaktor (Magnetik Contactor) yaitu peralatan listrik yang bekerja berdasarkan prinsip induksi elektromagnetik. Pada kontaktor terdapat sebuah belitan yang mana bila dialiri arus listrik akan timbul medan magnet pada inti besinya, yang akan membuat 
kontaknya tertarik oleh gaya magnet yang timbul tadi. Kontak Bantu NO (Normally Open) akan menutup dan kontak Bantu NC (Normally Close) akan membuka.

Kontak pada kontaktor terdiri dari kontak utama dan kontak Bantu. Kontak utama digunakan untuk rangkaian daya sedangkan ko-ntak Bantu digunakan untuk rangkaian kontrol. Didalam suatu kontaktor elektromagnetik terdapat kumparan utama yang terdapat pada inti besi. Kumparan hubung singkat berfungsi sebagai peredam getaran saat kedua inti besi saling melekat.

Apabila kumparan utama dialiri arus, maka akan timbul medan magnet pada inti besi yang akan menarik inti besi dari kumparan hubung singkat yang dikopel dengan kontak utama dan kontak Bantu dari kontaktor tersebut. Hal ini akan mengakibatkan kontak utama dan kontak bantunya akan bergerak dari posisi normal dimana kontak NO akan tertutup sedangkan NC akan terbuka.

Selama kumparan utama kontaktor tersebut masih dialiri arus, maka kontak-kontaknya akan tetap pada posisi operasinya. Apabila pada kumparan kontaktor diberi tegangan yang terlalu tinggi maka akan menyebabkan berkurangnya umur atau merusak kumparan kontaktor tersebut. Tetapi jika tegangan yang diberikan terlalu rendah maka akan menimbulkan tekanan antara kontak-kontak dari kontaktor menjadi berkurang. Hal ini menimbulkan bunga api pada permukaannya serta dapat merusak kontakkontaknya. Besarnya toleransi tegangan untuk kumparan kontaktor adalah berkisar $85 \%$ - $110 \%$ dari tegangan kerja kontaktor.

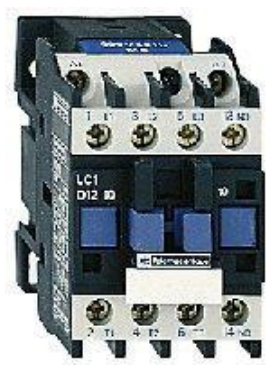

Gambar 2.18 Kontaktor (Magnetik Contactor)
3. Relay

Relay adalah saklar elektronik yang dapat membuka atau menutup rangkaian dengan menggunakan kontrol dari rangkaian elektronik lain. Sebuah relay tersusun atas kumparan, pegas, saklar (terhubung pada pegas) dan 2 kontak elektronik (normally close dan normally open)

a. Normally close (NC): saklar terhubung dengan kontak saat relay tidak aktif atau dapat dikatakan saklar dalam kondisi terbuka.

b. Normally open (NO): saklar terhubung dengan kontak saat relay aktif atau dapat dikatakan saklar dalam kondisi tertutup.

Berdasarkan pada prinsip dasar cara kerjanya, relay dapat bekerja karena adanya medan magnet yang digunakan untuk menggerakkan saklar.

Saat kumparan diberikan tegangan sebesar tegangan kerja relay maka akan timbul medan magnet pada kumparan karena adanya arus yang mengalir pada lilitan kawat. Kumparan yang bersifat sebagai elektromagnet ini kemudian akan menarik saklar dari kontak NC ke kontak NO.

Jika tegangan pada kumparan dimatikan maka medan magnet pada kumparan akan hilang sehingga pegas akan menarik saklar ke kontak NC.
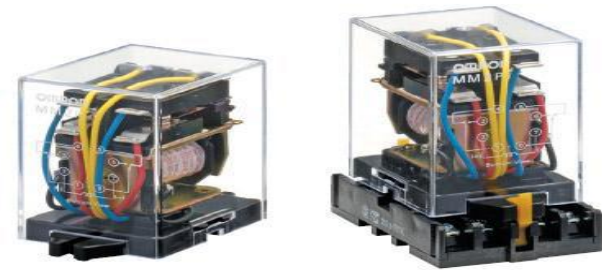

Gambar 2.19 Relay

\section{Inverter}

Inverter digunakan untuk mengubah sumber DC menjadi sumber AC, dimana tegangan yang di hasilkan dapat merupakan nilai yang konstan atau variabel. Suatu inverter sumber tegangan (Voltage Source 
Inverter = VSI) jika tegangan keluarannya konstan, inverter sumber arus (Current Source Inverter $=C S I$ ) jika arus keluarannya konstan, dan inverter hubungan DC yang variabel (variabel DC linked inverter) jika tegangan keluarannya dapat di kontrol atau di kendalikan lebih besar ataupun lebih kecil dari tegangan input.

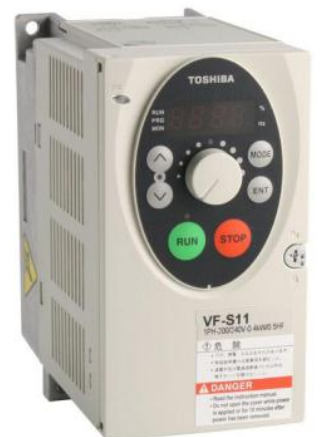

Gambar 2.20 Inverter Tipe Toshiba VF-S11

Fungsi Inverter adalah untuk merubah kecepatan motor AC dengan cara merubah Frekuensi Outputnya:

$\mathrm{f}=$ frekuensi $(\mathrm{Hz})$

$p=$ jumlah kutub

Jika sebelumnya banyak menggunakan sistem mekanik, kemudian beralih ke motor slip maka saat ini banyak menggunakan semikonduktor.

Tidak seperti softstarter yang mengolah level tegangan, inverter menggunakan frekuensi tegangan keluaran untuk mengatur speed motor pada kondisi ideal (tanpa slip).

Merubah kecepatan motor dengan Inverter akan membuat:

- Torsi lebih besar

- Presisi kecepatan dan torsi yang tinggi

- Kontrol beban menjadi dinamis untuk berbagai aplikasi motor

- Dapat berkombinasi dengan PLC/Programmable Logic Control untuk fungsi otomasi dan regulasi

- Menghemat energi

- Menambah kemampuan monitoring

- Hubungan manusia dengan mesin (interface) lebih baik
- Sebagai pengaman dari motor, mesin (beban) bahkan proses dll.

Semakin besar daya motor maka makin besar torsi yang dihasilkan dan makin kuat motor menggerakkan beban, Torsi dapat ditambah dengan menggunakan gear box (cara mekanis) dan Inverter (cara elektronik).

Proses di industri seringkali memerlukan tenaga penggerak dari motor listrik yang perlu diatur kecepatan putarnya untuk menghasilkan torsi dan tenaga/daya yang diinginkan. Torsi adalah gaya putar yang dihasilkan oleh motor listrik untuk memutar beban.

Kelebihan Torsi (over torque) terjadi jika torsi beban lebih besar dari Torsi nominal, pada $80 \%$ aplikasi terjadi pada saat kecepatan rendah atau saat start awal. Jika torsi inverter rendah akan mengakibatkan:

- Dinamika gerakan rendah (tidak memungkinkan gerakan beban yg kompleks).

- Motor sering overload (motor rusak atau thermal overload relay trip).

- Hentakan mekanis (Mesin/beban rusak, perlu perawatan intensif).

- Lonjakan arus (Motor rusak atau Breaker Trip).

- Presisi dalam proses hilang (Proses terancam).

- $\quad$ Proteksi tidak terjamin (Berbahaya.)

- Motor atau Inverter besar (Investasi bertambah)

Maka dapat disimpulkan, peranan inverter dalam proses suatu industri cukup penting. Karena dalam proses di industri seringkali memerlukan tenaga penggerak dari motor listrik yang perlu diatur kecepatan putarnya untuk menghasilkan torsi dan tenaga/daya yang diinginkan.

\section{MCB (Miniature Circuit Breaker)}

Singkatan MCB adalah Mini Circuit Breaker yang memiliki fungsi sebagai alat pengaman arus lebih. MCB ini memproteksi 
arus lebih yang disebabkan terjadinya beban lebih dan arus lebih karena adanya hubungan pendek. Dengan demikian prinsip dasar bekerjanya yaitu untuk pemutusan hubungan yang disebabkan beban lebih dengan relai arus lebih seketika digunakan elektromagnet.

Bila bimetal ataupun elektromagnet bekerja, maka ini akan memutus hubungan kontak yang terletak pada pemadam busur dan membuka saklar. MCB untuk rumah seperti pada pengaman lebur diutamakan untuk proteksi hubungan pendek, sehingga pemakaiannya lebih diutamakan untuk mengamankan instalasi atau konduktornya. Sedang MCB pada APP diutamakan sebagai pembawa arus dengan karakteristik $\mathrm{CL}$ (current limiter) disamping itu juga sebagai gawai pengaman arus hubung pendek yang bekerja seketika.

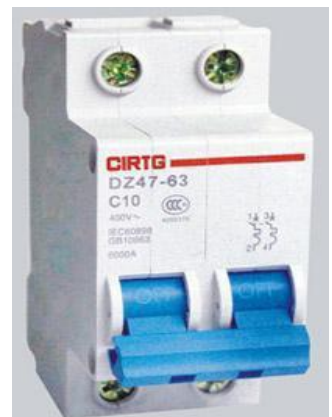

Gambar 2.21 MCB (Miniature Circuit Breaker)

\section{Thermal Overload Relay (TOR)}

Adalah pengaman beban lebih atau overload yang digunakan pada instalasi beban motor listrik adalah TOR. Jika arus yang melaui penghantar yang menuju motor listrik melebihi kapasitas atau seting TOR, maka TOR drop atau terputus sehingga rangkaian yang menuju motor listrk terputus. TOR dihubungkan dengan kontaktor pada kontak utama (untuk seri magnet kontaktor tertentu).Rotasi kontak utamanya adalah 2,4,6 sebelum beban atau motor listrik.

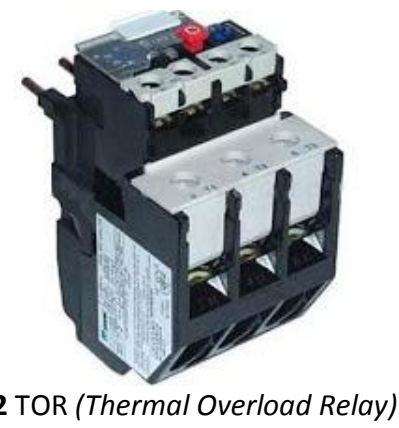

Beberapa penyebab terjadinya beban lebih:

- Beban mekanik pada motor listrik terlalu besar

- Arus start terlalu besar dan terlalu lama putaran nominal tercapai atau motor listrik berhenti secara mendadak

- Terjadi hubungan singkat pada motor listrik antara fasa dengan fasa,atau antara fasa dengan body

- Motor listrik bekerja hanya dengan dua fasa atau terbukanya salah satu fasa dari motor listrik tiga fasa.

Prinsip kerja termal beban berdasarkan panas atau temperature yang ditimbulkan oleh arus yang mengalir melalui elemenelemen pemanas bimetal. Jika panas berlebihan maka salah satu logam bimetal melengkung dan menggerakkan kontak mekanis pemutus rangkaian listrik (untuk bimetal seri tertentu).

\section{ANALISA dan PEMBAHASAN}

\subsection{Penanganan Sensor}

Sensor yang digunakan conveyor dalam penelitian ini adalah sensor photodioda. Banyaknya sensor yang digunakan suatu conveyor tergantung panjangnya conveyor tersebut. Jadi semakin panjang suatu conveyor semakin banyak sensor yang di guna-kan. Photodioda digunakan sebagai detektor cahaya dan LED (Light Emiting Dioda) yaitu dioda pemancar cahaya, yang digunakan sebagai sumber cahaya yang diletakkan pada suatu tempat dimana objek dapat dideteksi ketika memotong garis cahaya. Jadi apabila barang 
di atas conveyor tersebut menumpuk dan menghalangi sensor photodioda yang saling berhadapan tersebut maka conveyor tersebut akan berhenti. Berikut contoh gambar sensor photodioda yang digunakan PT. XYZ.

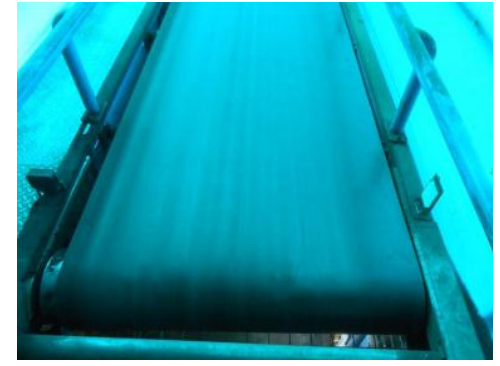

Gambar 3.1 Sensor Photodioda lity:

Indikasi ganda memastikan tinggi visibi-

- Kesesuaian dengan warna terdaftar dapat dipantau di delapan tingkat. (Deteksi Indikator tingkat)

- Memungkinkan penyesuaian halus antara halus atau diskriminasi kasar sementara pemantauan hasil yang diukur. (Indikator tingkat Threshold)

Stabil dan Powerfull Deteksi untuk Inline:

- Deteksi Stabil terjamin dengan ambang $\pm 10 \mathrm{~mm}$ untuk built-in jenis amplifier dan $\pm 4 \mathrm{~mm}$ untuk jenis serat optik.

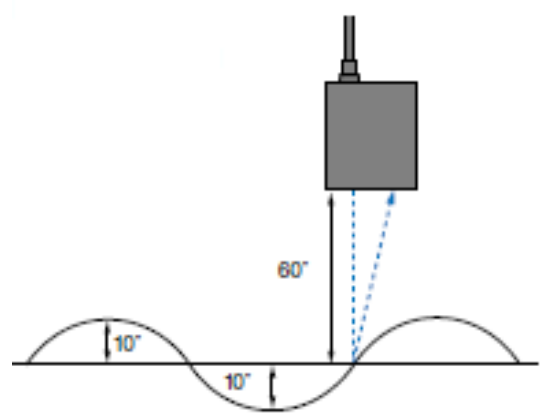

Gambar 3.2 Jarak sensor dengan benda

\section{Prinsip Deteksi:}

E3MC mendeteksi warna dengan memanfaatkan fakta bahwa refleksi rasio warna primer (yaitu merah, hijau atau biru) tercermin oleh objek bervariasi dengan chromatically objek. Dengan menggunakan hightech sebuah, multi-layer terpolarisasi penyaring yang disebut FAO (optik sudut gratis), E3MC memancarkan merah, hijau dan biru muda pada sumbu optik tunggal. E3MC menerima cahaya yang dipantulkan oleh penginderaan objek melalui penerima dan proses rasio merah-hijau-biru cahaya untuk membedakan warna obyek penginderaan.

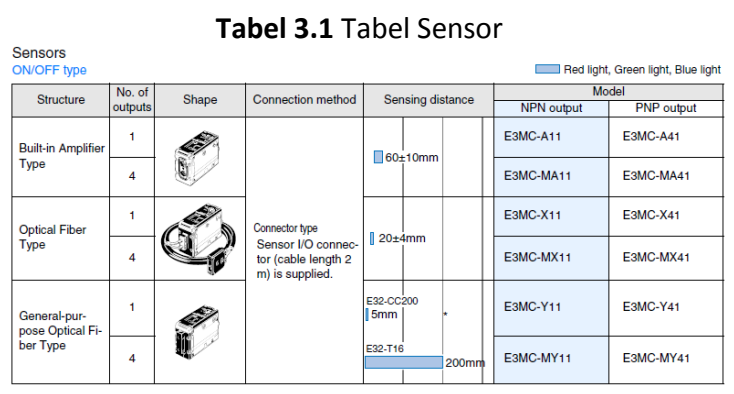

Tabel 3.2 Analog Output Type

\begin{tabular}{|l|c|c|c|c|}
\hline \multicolumn{1}{|c|}{ Analog output type } \\
\hline $\begin{array}{l}\text { Built-in Amplifier } \\
\text { Type }\end{array}$ & Shape & \multicolumn{2}{|c|}{ Sensing distance } & Model \\
\hline Optical Fiber Type & E3MC-A81 & & & \\
\hline $\begin{array}{l}\text { General-purpose } \\
\text { Optical Fiber Type }\end{array}$ & E3MC-X81 & & & \\
\hline
\end{tabular}

Tabel 3.3 Accessories Accessories (Order Separately) Sensor I/O Connectors

\begin{tabular}{|c|c|c|c|c|}
\hline Shape & \multicolumn{2}{|c|}{ Model } & Quantity & Remarks \\
\hline \multirow{2}{*}{$\mathbb{Q}(1) \square=\square=$} & \multicolumn{2}{|c|}{ E39-C1 2M (2 m) } & $1 \mathrm{pc}$. & Supplied with the product. \\
\hline & \multicolumn{2}{|c|}{ E39-C1 5M (5 m) } & $1 \mathrm{pc}$. & $\begin{array}{l}\text { Please place an order } \\
\text { when extending the cable. }\end{array}$ \\
\hline \multicolumn{5}{|c|}{ Mounting Brackets } \\
\hline Shape & Model & Quanti- & & Remarks \\
\hline$\Leftrightarrow$ & E39-L114 & 2 & \multicolumn{2}{|c|}{$\begin{array}{l}\text { For E3MC installation. } \\
\text { (Can be inclined to } 15^{\circ} \text { ) }\end{array}$} \\
\hline & E39-L115 & 1 & \multicolumn{2}{|c|}{ For DIN track installation. } \\
\hline
\end{tabular}

\subsection{Pengaturan Inverter}

Inverter merupakan sebuah alat pengatur kecepatan motor dengan mengubah nilai frekuensi dan tegangan yang masuk ke motor. Pengaturan nilai frekuensi dan tegangan ini dimaksudkan untuk mendapatkan kecepatan putaran dan torsi motor yang di inginkan atau sesuai dengan kebutuhan. 
Secara sederhana prinsip dasar inverter untuk dapat mengubah frekuensi menjadi lebih kecil atau lebih besar yaitu dengan mengubah tegangan $A C$ menjadi tegangan $D C$ kemudian dijadikan tegangan AC lagi dengan frekuensi yang berbeda atau dapat diatur.

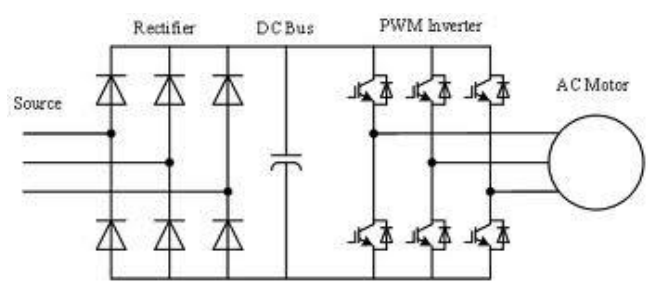

Gambar 3.3 Diagram Inverter

Untuk mengubah tegangan $A C$ menjadi DC dibutuhkan penyearah (converter AC-DC) dan biasanya menggunakan penyearah tidak terkendali (rectifier dioda) namun juga ada yang menggunakan penyearah terkendali (thyristor rectifier). Setelah tegangan sudah diubah menjadi DC maka diperlukan perbaikan kualitas tegangan DC dengan menggunakan tandon kapasitor sebagai perata tegangan. Kemudian tegangan DC diubah menjadi tegangan $A C$ kembali oleh inverter dengan teknik PWM (Pulse Width Modulation). Dengan teknik PWM ini bisa didapatkan amplitudo dan frekuensi keluaran yang diinginkan. Selain itu teknik PWM juga menghasilkan harmonisa yang jauh lebih kecil dari pada teknik yang lain serta menghasilkan gelombang sinusoidal, dimana kita tahu kalau harmonisa ini akan menimbulkan rugi-rugi pada motor yaitu cepat panas. Maka dari itu teknik PWM inilah yang biasanya dipakai dalam mengubah tegangan $D C$ menjadi $A C$ (inverter). Memang ada banyak cara untuk mengatur/mengurangi kecepatan motor seperti dengan gear box/ reducer. Namun mengatur kecepatan motor dengan inverter akan memperoleh banyak keuntungan yang lebih bila dibandingkan dengan cara-cara yang lain. Seperti: jangkauan yang luas untuk pengaturan kecepatan dan torsi motor, mempunyai akselerasi dan deselerasi yang dapat diatur, mempermudah proses monitoring/ pengecekan, sistem proteksi motor yang baik, mengurangi arus starting motor dan menghemat pemakaian energi listrik, memperhalus start awal motor dll.

Pemilihan inverter yang benar tentunya dengan memperhatikan spesifikasi dari motor serta keperluan dalam pemakaian inverter itu sendiri. seperti dengan memperhatikan daya motor, tegangan motor, frekuensi motor. contohnya anda memiliki motor 3 phase $3 \mathrm{KW}$, maka anda perlu menggunakan inverter dengan spesifikasi daya diatas $3 \mathrm{kw}$ seperti 3,2 kw atau 3,3 kw dan tentunya tegangan keluaran dari inverter harus sama dengan tegangan motor. sebenarnya anda juga bisa menggunakan inverter dengan daya $3 \mathrm{kw}$ untuk motor $3 \mathrm{kw}$ tapi dengan 20 syarat anda menggunakan motor tersebut dengan beban yang kecil atau dengan kata lain motor tidak digunakan dengan daya maksimal. Jadi penting untuk mengetahui arus pada motor saat dijalankan dengan beban, untuk setingan ampere pada inverter sebagai proteksi motor, serta untuk menghitung daya beban yang berguna dalam pemilihan inverter.

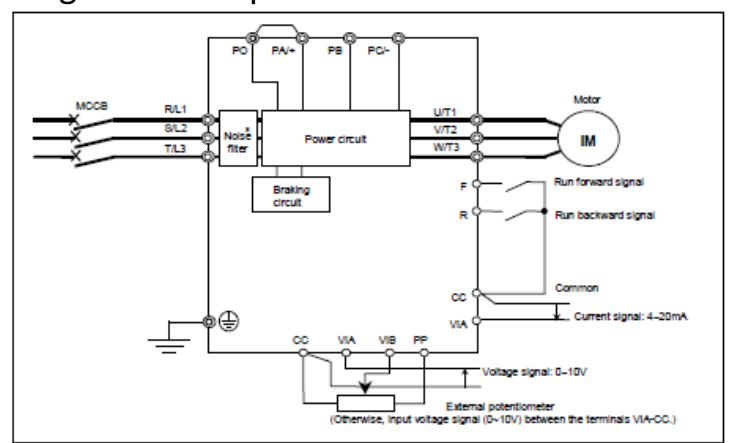

Gambar 3.4 Wiring Inverter

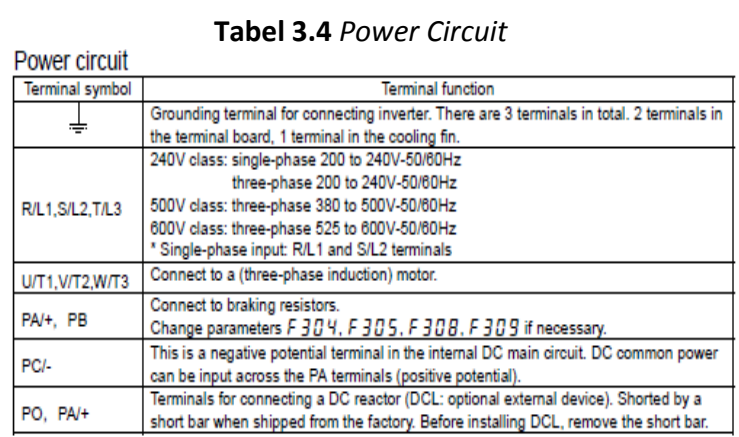


Tabel 3.5 Parameter Input Output

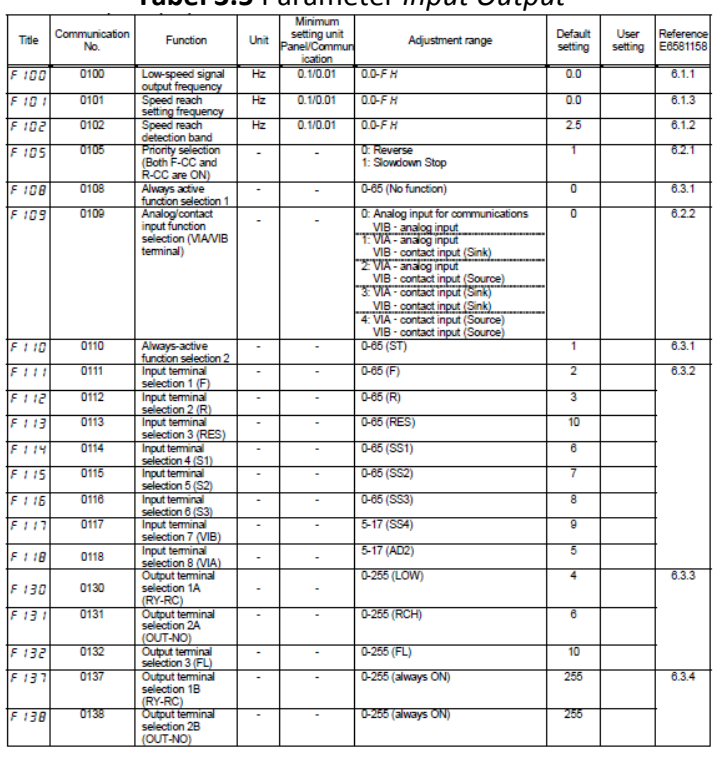

\subsection{Sistem Kontrol}

Sistem yang terdiri dari beberapa elemen sistem yang dapat mengendalikan/ mengatur suatu besaran tertentu. yang dapat diidentifikasi atau ditengarai terdiri dari minimal 2 (dua) bagian utama, yaitu:

- $\quad$ Plant/proses, obyek yang dikendalikan

- Kontroller/Pengendali, yang mengendalikan

Definisi-Definisi:

- Input (Set Point, Reference)

Respon sistem yang diinginkan

- Output

Respon sistem sebenarnya

- Plant

Obyek yang dikontrol atau objek fisik yang dikendalikan (tungku pemanas, reaktor nuklir, pesawat ruang angkasa)

- Proses

Operasi yang dikontrol

- Gangguan

Sinyal yang mempunyai pengaruh merugikan terhadap keluaran sistem

- Umpan Balik

Kemampuan suatu sistem untuk membandingkan outputnya dengan inputnya (output yang ingin dicapai) sehingga selisih antara output dengan input (sinyal galat), akan menyebabkan output berubah sehingga menyamai input.

\subsection{Sistem Kontrol Otomatis}

Suatu sistem kontrol otomatis dalam suatu proses kerja berfungsi mengendalikan proses tanpa adanya campur tangan manusia (otomatis). Ada dua sistem kontrol pada sistem kendali/kontrol otomatis yaitu:

A. Open Loop (Loop Terbuka)

Suatu sistem kontrol yang keluarannya tidak berpengaruh terhadap aksi pengontrolan. Dengan demikian pada sistem kontrol ini, nilai keluaran tidak di umpan-balikkan ke parameter pengendalian.

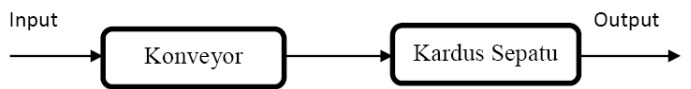

Gambar 3.5 Diagram Blok Sistem Pengendalian Loop Terbuka

Karakteristik Sistem kendali loop terbuka:

- output tidak diukur maupun di umpanbalikkan

- ketepatan hasil bergantung pada kalibrasi.

- hubungan antara output dan input diketahui

- tidak ada 'internal disturbance' maupun 'eksternal disturbance'

- terkait dengan waktu

Kelebihan:

- konstruksinya sederhana dan perawatannya mudah

- lebih murah

- tidak ada persoalan kestabilan

- cocok untuk keluaran yang sukar diukur /tidak ekonomis (contoh: untuk mengukur kualitas keluaran pemanggang roti)

Kelemahan:

- Tidak dapat memberikan kompensasi/ koreksi jika ada gangguan

- gangguan dan perubahan kalibrasi

- untuk menjaga kualitas yang diinginkan perlu kalibrasi ulang dari waktu ke waktu. 
Contoh:

- Van Belt

- Motor \& Gear Box

\section{B. Close Loop (Loop Tertutup)}

Suatu sistem kontrol yang sinyal keluarannya memiliki pengaruh langsung terhadap aksi pengendalian yang dilakukan. Sinyal error yang merupakan selisih dari sinyal masukan dan sinyal umpan balik (feedback), lalu diumpankan pada komponen pengendalian (controller) untuk memperkecil kesalahan sehingga nilai keluaran sistem semakin mendekati harga yang diinginkan. Keuntungan sistem loop tertutup adalah adanya pemanfaatan nilai umpan balik yang dapat membuat respon sistem kurang peka terhadap gangguan eksternal dan perubahan internal pada parameter sistem Kerugiannya adalah tidak dapat mengambil aksi perbaikan terhadap suatu gangguan sebelum gangguan tersebut mempengaruhi nilai prosesnya.

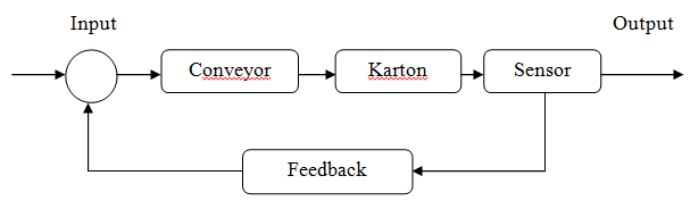

Gambar 3.6 Diagram Blok Sistem Kontrol Tertutup

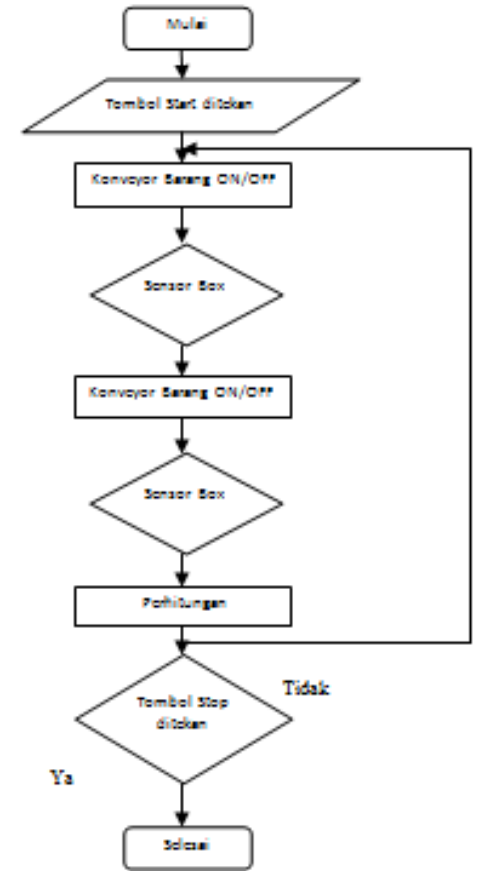

Gambar 3.7 Diagram Alir Konveyor Penghitung Barang

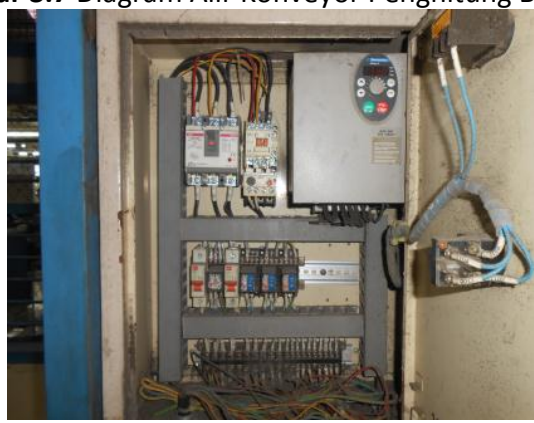

Gambar 3.8 Komponen di Panel Box

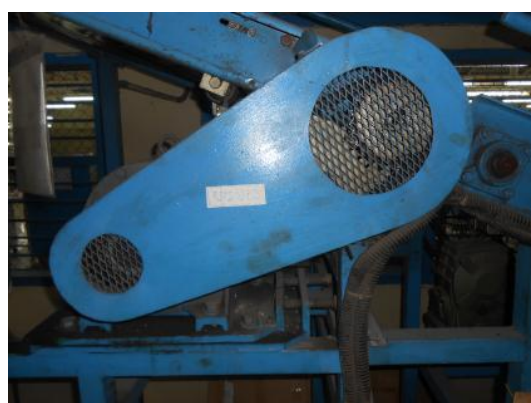

Gambar 3.9 Sambungan Gear Box dengan Conveyor Belt 


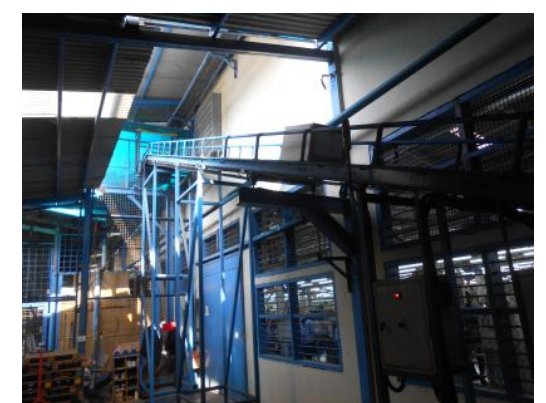

Gambar 3.10 Conveyor Belt

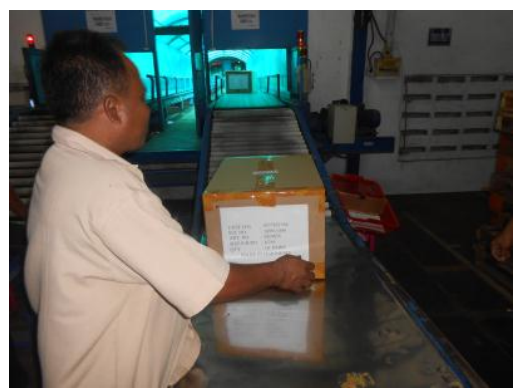

Gambar 3.11 Penerimaan Dus Berisi Produk Dari Produksi Ke Gudang

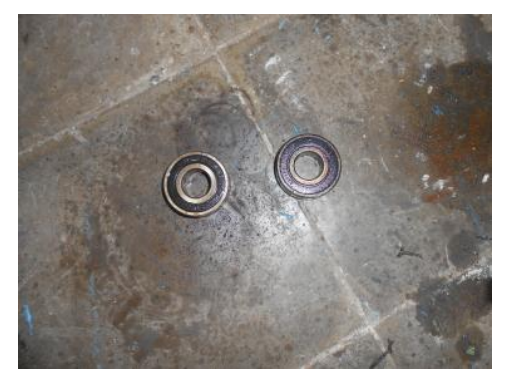

Gambar 3.12 Bearing yang Sudah Rusak (Haus)

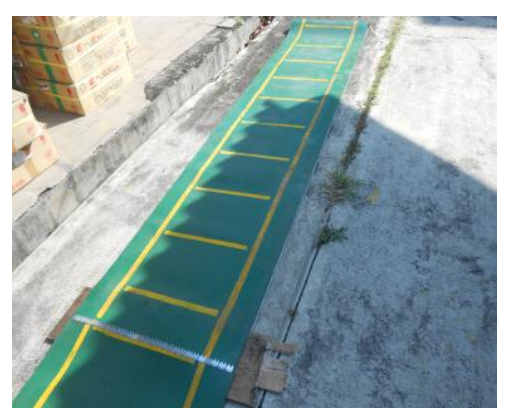

Gambar 3.13 Penyambungan Van Belt yang putus menggunakan Steel Belt Lacing

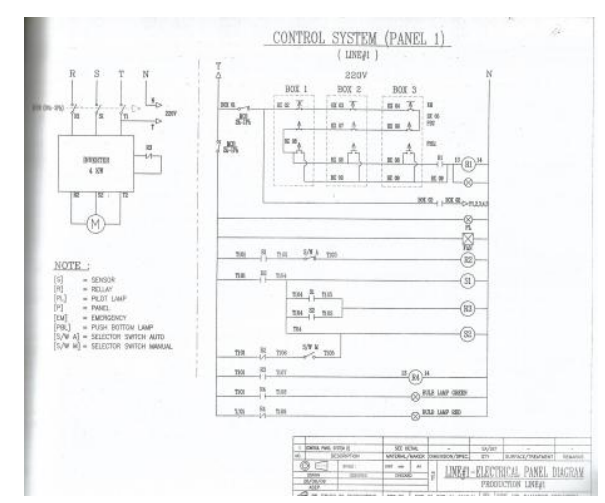

Gambar 3.14 Diagram Kelistrikan Panel Box 1

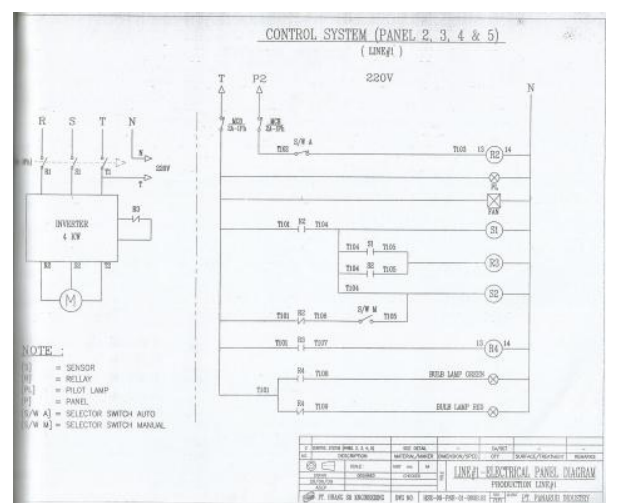

Gambar 3.15 Diagram Kelistrikan Panel Box 2, 3, 4 \& 5

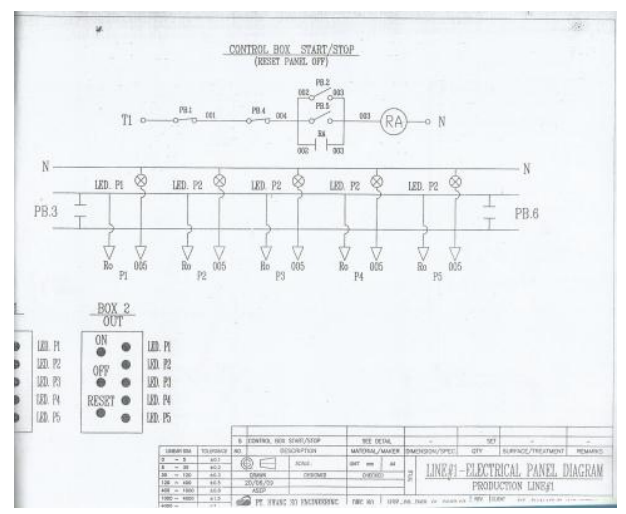

Gambar 3.15 Diagram Kontrol Box Start/Stop

\section{KESIMPULAN}

Dari hasil kerja praktek yang penulis lakukan di PT. XYZ, ada beberapa kesimpulan sebagai berikut ini:

1. Dalam pembuatan conveyor belt di perhatikan tempat meletakan sensor, karena sangat berpengaruh apabila bergeser sedikit pun. 
2. Penyesuaian kekuatan torsi kekuatan motor harus di sesuaikan dengan gearbox yang di pasang.

3. Dalam penggunaan inverter di harapkan menyesuaikan kondisi motor dan gearbox-nya.

4. Dari penelitian ini diperoleh kesimpulan dalam 1 hari conveyor belt tersebut dapat membawa kurang lebih 600 karton pada speed inverter 28-32 Rpm yang sepatu dari produksi ke gudang, dibandingkan dengan membawa manual yang membutuhkan waktu yang lama dan tenaga yang kuat.

\section{DAFTAR PUSTAKA}

Muchsin, Ismail. Pusat Pengembangan Bahan Ajar-UMB Elektronika \& Motor Listrik. ELETRONIKA \& MOTOR LIST ELETRONIKA \& MOTOR.
Mohamad Yamin, Widyo Purwoko. Perencanaan Gear Box Dan Analisis Statik Rangka Conveyor Menggunakan Software CATIA V5.

Muslimin, Zaenab. Pengontrolan Motor Induksi Tiga Fasa dengan Inverter Berbasis Mikrokontroler AT89S51, Universitas Hasanuddin, 2009.

Triyono, Modul Dasar Sistem Kontrol, Teknik Elektro FT-UMT, 2014.

Manual book, Rubber Belt Conveyor Ass'y, PT. Hwang So Engineering, 2009-2010.

Data Sheet Inverter.

Data Sheet Sensor. 